\title{
QUÍMICA VERDE, OS DESAFIOS DA QUÍMICA DO NOVO MILÊNIO
}

\author{
Alexandre G. S. Prado \\ Instituto de Química, Universidade de Brasília, CP 4478, 70919-970 Brasília - DF
}

Recebido em 23/9/02; aceito em 31/3/03

\begin{abstract}
GREEN CHEMISTRY, THE CHEMICAL CHALLENGES OF THE NEW MILLENIUM. The fundamental concepts of the green chemistry are highlighted in order to present the enormous number of challenges to develop a new chemistry in research, industry and education. The practice of an environmental friendly chemistry are presented to improve the economics of chemical manufacturing and to enhance the much-tarnished image of chemistry and to present the opportunities to discover and apply this new chemistry. The challenges and opportunities of green chemistry in the world and Brazil are introduced and discussed in this report.
\end{abstract}

Keywords: green chemistry; clean chemistry; sustainable chemistry.

\section{INTRODUÇÃO}

A química tem uma grande participação nos dias atuais com os inúmeros produtos fundamentais à humanidade. A sua presença pode ser destacada desde diversos combustíveis ao mais complexos medicamentos. Porém, a produção química também gera inúmeros inconvenientes, como a formação de subprodutos tóxicos e a contaminação do ambiente e do próprio homem expostos a estes xenobió$\operatorname{ticos}^{1,2}$. A preocupação com estes inconvenientes pode ser claramente observada pois, nos últimos anos, cresce continuamente a pressão sobre as indústrias químicas, tanto através da sociedade civil, como das autoridades governamentais, no sentido de aprimorar o desenvolvimento de processos, que sejam cada vez menos prejudiciais ao meio ambiente ${ }^{3,4}$. Dentro da problemática industrial vigente, um dos principais problemas que se destaca é o grande volume de efluentes tóxicos produzidos por vários processos químicos. A emissão de contaminantes pode ser minimizada através de diversos caminhos, tais como o emprego de reagentes alternativos apropriados ${ }^{5}$, o aumento da seletividade para maximizar o uso dos materiais de parti$\mathrm{da}^{6}$, a utilização de catalisadores para facilitar a separação do produto final da mistura, bem como a reciclagem dos reagentes e catalisadores empregados no processo ${ }^{6-8}$. Dentre as áreas de pesquisa enfocadas para estas finalidades, têm-se destacado muito nos últimos anos a preparação de catalisadores sólidos, com o firme propósito da remoção de contaminantes dispersos em efluentes, bem como na catálise de reações químicas com o objetivo da maximização das reações e redução da formação de subprodutos indesejáveis durante o processo reacional ${ }^{9,10}$. Estes conceitos devem estar fixados em todos os estudantes de química com a intenção formar profissionais capacitados para os novos conceitos científicos e tecnológicos responsáveis pela sustentabilidade do planeta $^{11,12}$.

\section{O conceito}

Dentro dos princípios da necessidade de um desenvolvimento sustentável, tem-se como regra que a química deve manter e melhorar a qualidade de vida. $\mathrm{O}$ grande desafio é a continuidade do desenvolvi-

e-mail: agsprado@unb.br mento, diminuindo os danos causados ao meio ambiente. Tal fato requer uma nova conduta química para o aprimoramento dos processos, com o objetivo fundamental da geração cada vez menor de resíduos e efluentes tóxicos, bem como da menor produção de gases indesejáveis ao ambiente ${ }^{3,4}$. Este novo caminho a ser delineado pela química é denominado como química sustentável ou química verde: "A criação, o desenvolvimento e a aplicação de produtos e processos químicos para reduzir ou eliminar o uso e a geração de substâncias tóxicas" ${ }^{4}$.

A química verde tem a preocupação do desenvolvimento de tecnologias e processos incapazes de causar poluição. Idealmente, a aplicação dos princípios da química verde conduz à regulamentação, ao controle para não causar a uma remediação desnecessária ${ }^{8}$. Além dos benefícios ambientais, tal pensamento apresenta também um impacto econômico graças à diminuição de gastos com o armazenamento e tratamento de resíduos, a descontaminação e o pagamento de indenizações ${ }^{4}$.

O questionamento global sobre os danos gerados ao planeta por uma miríade de atividades humanas ${ }^{13}$ tem se apresentado cada vez mais em destaque na mídia. A resposta encontrada para ajudar na solução destes problemas está baseada em uma combinação de fatores, entre os quais destacam-se os econômicos, científicos, bem como os sociais. Assim, a adoção da química verde é só mais uma das iniciativas para a prevenção da poluição desenfreada. Este novo pensamento científico incentiva tal combinação e a implantação da química verde nos currículos e na prática científica, bem como aplicá-la em escala comercial e industrial ${ }^{4}$.

\section{Os doze princípios}

A emergência da química verde na educação e na pesquisa está sendo suportada por sociedades científicas, governos e indústrias ${ }^{14}$. Os princípios da prática química guiada pela preocupação com a qualidade de vida e com o meio ambiente formam os doze princípios da química verde: 1) prevenção, é melhor prevenir a formação de subprodutos do que tratá-los posteriormente; 2) economia de átomos, os métodos sintéticos devem ser desenvolvidos para maximizar a incorporação dos átomos dos reagentes nos produtos finais desejados; 3) sínteses com compostos de menor toxicidade, sempre que possível deve-se substituir compostos de alta toxicidade por compostos de menor toxicidade nas reações químicas; 4) desenvolvimento de compostos seguros, os produtos químicos deverão ser desenvol- 
vidos para possuirem a função desejada, apresentando a menor toxicidade possível; 5) diminuição de solventes e auxiliares, a utilização de substâncias auxiliares (solventes, agentes de separação, etc) deverá ser evitado quando possível, ou usadas inócuas no processo; 6) eficiência energética, os métodos sintéticos deverão ser conduzidos sempre que possível à pressão e temperatura ambientes, para diminuir a energia gasta durante um processo químico que representa um impacto econômico e ambiental; 7) uso de substâncias recicladas, os produtos e subprodutos de processos químicos deverão ser reutilizados sempre que possível; 8) redução de derivativos, a derivatização (uso de reagentes bloqueadores, de proteção ou desproteção, modificadores temporários) deverá ser minimizada ou evitada quando possível, pois estes passos reacionais requerem reagentes adicionais e, conseqüentemente, podem produzir subprodutos indesejáveis; 9) catálise, a aplicação de catalisadores para aumentar a velocidade e o rendimento dos processos químicos; 10) desenvolvimento de compostos para degradação, produtos químicos deverão ser desenvolvidos para a degradação inócua de produtos tóxicos, para não persistirem no ambiente; 11) análise em tempo real para a prevenção da poluição, as metodologias analíticas precisam ser desenvolvidas para permitirem o monitoramento do processo em tempo real, para controlar a formação de compostos tóxicos; 12) química segura para a prevenção de acidentes, as substâncias usadas nos processos químicos deverão ser escolhidas para minimizar acidentes em potencial, tais como explosões e incêndios ${ }^{8,11,15-17}$.

\section{Áreas de atuação}

O primeiro desafio é a conscientização para o desenvolvimento de tecnologias limpas no lugar das atuais. As iniciativas da química verde englobam todas as áreas da ciência, sempre considerando os princípios fundamentais de sustentabilidade. O desenvolvimento desta química implica: i) no uso de reagentes alternativos e renováveis, com o objetivo central de diminuir os reagentes tóxicos e nãobiodegradáveis no ambiente; ii) no uso reagentes inócuos durante o processo de síntese para evitar perdas indesejáveis, aumentando o rendimento da produção; iii) na mudança de solventes tóxicos por outros solventes alternativos; iv) no melhoramento dos processos naturais, tais como biosínteses, biocatálises; v) no desenvolvimento de compostos seguros, isto é, com baixa toxicidade; vi) no desenvolvimento de condições reacionais para se obter maior rendimento e menor geração de subprodutos e, por final, vii) na minimização do consumo de energia ${ }^{1,3}$.

\section{Sólidos ácidos e básicos aplicados em catálise}

O principal problema causado pelos processos químicos é o elevado volume de efluentes e resíduos tóxicos gerados por processos não específicos e não seletivos, os quais geram enormes quantidades de subprodutos indesejáveis, que são descartados. O melhoramento na eficiência destes processos pode ser feito por diversos caminhos, tais como o uso de reagentes alternativos e a aplicação de catalisadores. Porém, a aplicação de catalisadores apresenta o inconveniente da separação catalisador/produto na mistura reacional durante o processo, além do mais, os processos de extração dos catalisadores geralmente os destroem ${ }^{7,18,19}$.

Uma das áreas de pesquisa que tem apresentado grande aumento de interesse neste contexto é a aplicação de reagentes suportados em matrizes sólidas, como meio alternativo de se obter catalisadores. A preparação de catalisadores sólidos permite sua aplicação nas reações com a grande vantagem de sua fácil separação do meio reacional e de sua capacidade em ser reciclado. Além do mais, estes compostos ainda podem ser aplicados na remoção dos contaminantes despe- jados em efluentes. Os reagentes suportados em matrizes sólidas também apresentam maior estabilidade térmica e química. As habilidades destes compostos imobilizados sugerem sua alta aplicabilidade em processos reacionais, com o forte propósito de se aumentar a eficiência das reações e diminuir a quantidade de resíduos e subprodutos durante os processos químicos ${ }^{7,18,19}$.

Os suportes também devem apresentar alta área superficial com o objetivo da acessibilidade dos sítios ativos destes materiais para que a catálise seja eficaz. Dentre os diversos suportes sólidos, devese destacar a sílica gel e os óxidos mistos, devido à alta estabilidade térmica e química, bem como bons valores de área superficial7 ${ }^{7,18,19}$.

Os catalisadores sólidos podem ser obtidos através de grande variedade de metodologias, tais como a organofuncionalização da sílica com organossilanos, que envolve a reação de trialcoxissilanos com os grupos silanóis dispersos na superfície da sílica, formando o composto modificado e liberando o álcool correspondente (Figura $1)$.
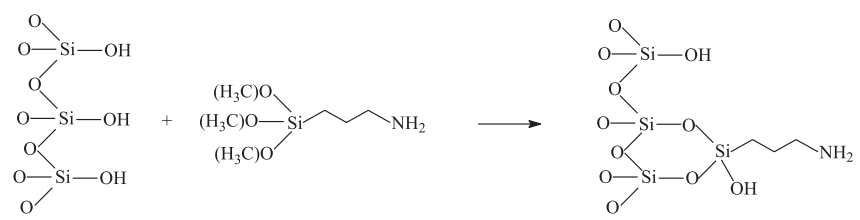

Figura 1. Modificação da sílica gel usando aminopropiltrimetoxissilano

Atualmente, a metodologia que tem sido extremamente usada é a produção de catalisadores sólidos, através do processo sol-gel na presença de agentes direcionadores, com o objetivo de obtenção dos materiais mesoestruturados. O processo sol-gel de obtenção de catalisadores sólidos permite dois caminhos bem definidos para a produção destes compostos: a pós-modificação e a funcionalização da sílica durante o processo de co-condensação.

A reação pelo processo sol-gel ocorre através da co-condensação entre grupos silanóis, que são formados na hidrólise, e a conseqüente polimerização para chegar ao produto final, a presença do direcionador ao meio funciona na formação de uma micela. Neste processo a micela é envolta pelo reagente tetraetilortossilicato, $\mathrm{Si}(\mathrm{OEt})_{4}$, que também permite a agregação do agente sililante, antes que ocorra o direcionamento da co-condensação da estrutura inorgânica, fato que acarreta o direcionamento estrutural, para que sejam formados os poros. A remoção do surfactante pode ser feita por calcinação, via extração com etanol ou ácido quente ${ }^{20-23}$.

As sílicas podem ser modificadas com compostos que apresentem grupos ácidos ou básicos, com o objetivo de produzir sólidos ácidos e/ou básicos, que são capazes de promover catálises de diversas reações, bem como de interagir com contaminantes para a sua remoção de efluentes.

No processo de pós-funcionalização do material, primeiro é obtida a sílica mesoporosa pelo processo sol-gel com o auxílio de um agente direcionador e o agente catalisador desejado é ancorado posteriormente à sílica mesoporosa, como mostra a Figura 2.

No processo de funcionalização durante o processo sol-gel, o catalisador desejado é incorporado à sílica durante o próprio processo de co-condensação, conforme a Figura 3.

A metodologia de pós-modificação apresenta o inconveniente de empregar uma etapa a mais de reação e, também, o grau de funcionalização é bem menor que o método de funcionalização durante o processo sol-gel. Conseqüentemente, o desenvolvimento de catalisadores sólidos mesoestruturados tem sido obtido pelo procedimento de funcionalização durante a co-condensação. Esta 


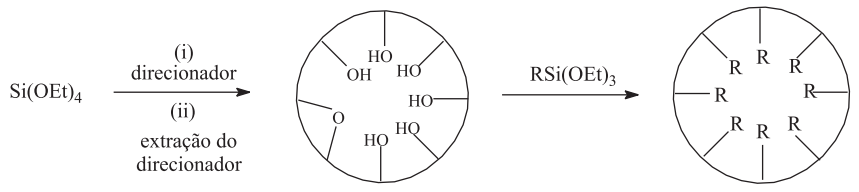

Figura 2. Preparação de sílica pós-organofuncionalizada pelo processo de sol-gel direcionado

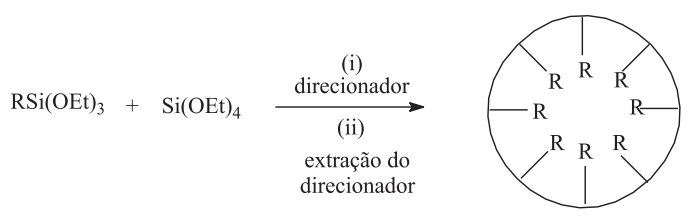

Figura 3. Preparação de sílica organofuncionalizada pelo processo sol-gel direcionado

metodologia envolve, geralmente, o tetraetilortossilicato (TEOS), um composto organossilano com um grupo funcional com habilidades catalíticas e um direcionador.

Os sólidos inorgânicos de estrutura porosa controlada apresentam melhores resultados do que as superfícies modificadas tradicionais. A versatilidade destes materiais está ligada diretamente à capacidade de se sintetizar uma variedade de estruturas híbridas, as quais podem ser obtidas por diversos rotas de síntese ${ }^{24-26}$. Consequientemente, as mais distintas moléculas têm sido usadas como direcionadores para a obtenção destes híbridos nestas rotas com reconhecido sucesso, dos quais pode-se destacar direcionadores catiônicos ${ }^{27}$, aniônicos ${ }^{24}$, bem como direcionadores neutros, tais como as aminas ${ }^{22}$, as diaminas ${ }^{25}$ e os poliéteres ${ }^{28}$. Todos estes direcionadores permitem a preparação de compostos mesoestruturados, que pode ser feita à base de sílica, aluminosilicatos, bem como dos mais diversos óxidos inorgânicos.

Estes compostos apresentam altos valores de área superficial e grande porosidade, o que resulta em materiais potencialmente aplicáveis em diversas áreas científico-tecnológicas ${ }^{18,19}$. Dentre esta grande quantidade de processos de obtenção de materiais mesoporosos, os métodos de síntese geralmente baseiam-se na utilização de surfactantes iônicos como direcionadores. No entanto, a remoção desta classe de direcionadores consiste na calcinação do material. Recentemente, esta mesma metodologia de obtenção de materiais mesoporosos foi desenvolvida com direcionadores neutros ${ }^{22,24,25,28}$.

A rota de síntese baseada na co-condensação em torno de direcionadores neutros apresenta a grande vantagem de evitar a calcinação no processo de remoção do direcionador, para que os grupos orgânicos ancorados sejam preservados ${ }^{19,20,22,28}$. Este procedimento facilita a funcionalização das matrizes inorgânicas durante o processo sol-gel e permite alto grau de ancoramento de grupos ativos desejados para as mais diversas aplicações científico-tecnológicas ${ }^{19,20,29}$. Os direcionadores neutros são moléculas de características peculiares, os quais apresentam uma cabeça polar e uma cauda apolar, resultando na formação de micelas em solventes polares. A parte apolar, devido à sua hidrofobicidade, direciona-se no centro da esfera formada pela micela para evitar o contato com a água, enquanto a parte polar interage diretamente com as moléculas de água ${ }^{19}$. O diâmetro das micelas depende diretamente da natureza do surfactante utilizado como direcionador da reação, o qual varia de 2 a $4 \mathrm{~nm}^{19,20,29}$.

Dentre os diversos métodos para obtenção de materiais mesoporosos modificados com moléculas orgânicas, deve-se destacar uma elegante rota de síntese. Neste caso, os compostos orgânicos são ancorados à matriz inorgânica durante o próprio processo de cocondensação do processo sol-gel, para a obtenção dos materiais híbridos orgânico-inorgânicos que podem apresentar as propriedades catalíticas de interesse ${ }^{30-33}$.

A aplicação direta deste processo é a preparação de catalisadores heterogêneos a partir da imobilização de catalisadores homogêneos convencionais na superfície da sílica. A vantagem do ancoramento dos catalisadores homogêneos na sílica é a redução da perda destes compostos durante o processo reativo e a otimização das reações. Estas sílicas mesoporosas obtidas pelo processo sol-gel apresentam alta área superficial que é excelente para processos catalíticos ${ }^{18,19}$.

A imobilização de ácidos de Lewis e de Brönsted nas sílicas permite a utilização destes novos materiais, denominados de sólidos ácidos, em diversos processos catalíticos em reações orgânicas convencionais, conforme descrito na Figura $4^{34,35}$.

A imobilização de bases de Lewis e de Brönsted também permite a formação de vários catalisadores heterogêneos, denominados de sólidos básicos, que são extremamente aplicados em diversas reações orgânicas, conforme descrito na Figura $5^{34,35}$.

Outra aplicação direta destes materiais em química verde é o uso destes sólidos ácidos e básicos para a remoção de contaminantes de

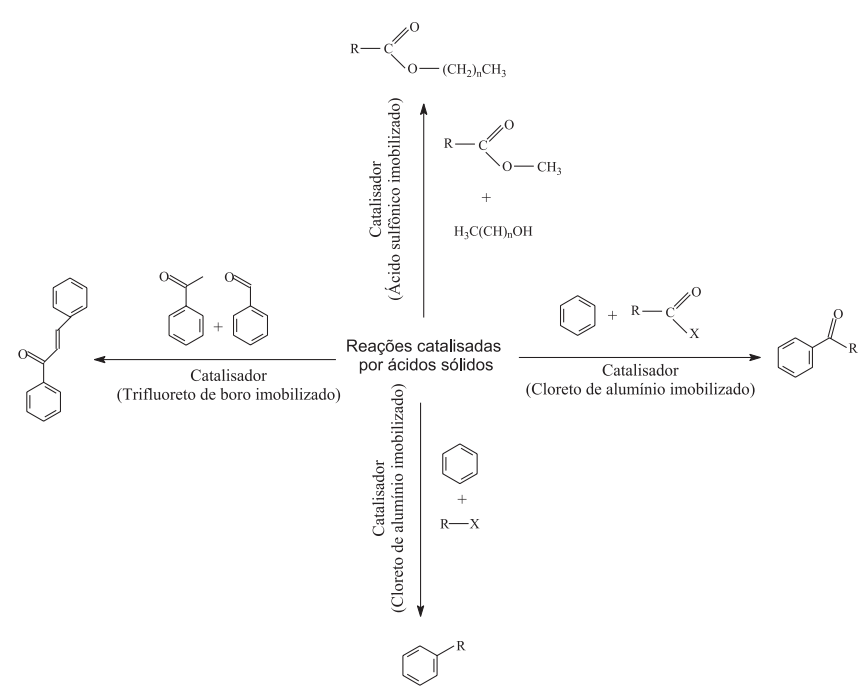

Figura 4. Algumas reações catalisadas por sólidos ácidos

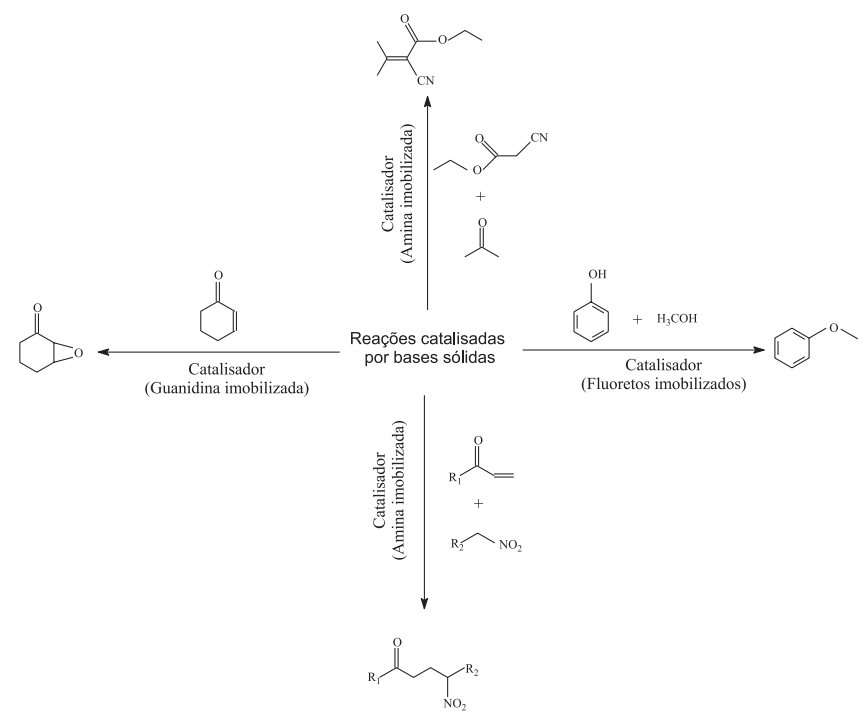

Figura 5. Algumas reações catalisadas por sólidos básicos 
efluentes $^{36-38}$. Como estes materiais apresentam grupos ácidos e/ou básicos dispersos em sua estrutura, devem interagir com compostos ácidos ou básicos permitindo, assim, a remoção de contaminantes, desde cátions e ânions até pesticidas e corantes, conforme esquematizado na Figura 6.

(a)

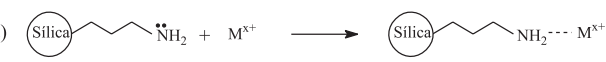

(b)
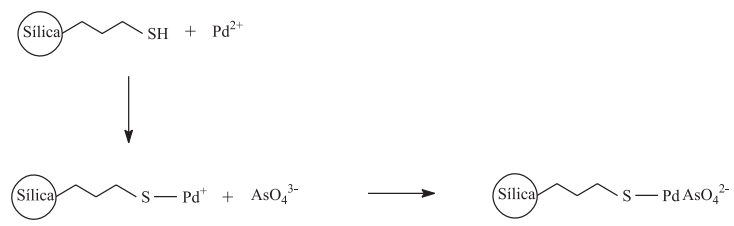

(c)

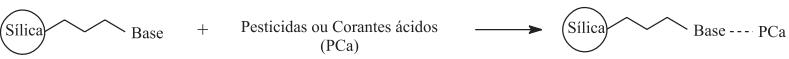

(d)

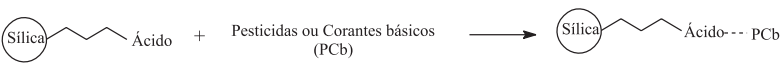

Figura 6. Esquemas propostos para remoção de contaminantes utilizando as sílicas hexagonais mesoporosas modificadas: (a) adsorção de cátions por sílica modificada com o grupo amina; (b) adsorção de paládio e posterior adsorção de arsenato por sílica modificada com o grupo tiol; (c) adsorção de corantes e pesticidas ácidos por sílica modificada com um grupo básico $e(d)$ adsorção de corantes e pesticidas básicos por sílica modificada com um grupo ácido

\section{Reações livres de solventes}

Muitas reações orgânicas têm sido conduzidas usando catalisadores sólidos juntamente com a irradiação microondas ou com a utilização de fluidos supercríticos, com o objetivo de se desenvolver de processos de reações orgânicas sem solventes orgânicos ${ }^{39}$. A utilização da água em condições extremas, a temperaturas acima de $200{ }^{\circ} \mathrm{C}$, forma um fluido supercrítico, o qual permite a solubilização de moléculas apolares e de compostos orgânicos. Esta solubilização permite o desenrolar das reações orgânicas, na ausência total de solventes orgânicos indesejáveis ao meio ambiente ${ }^{40}$.

\section{Microondas}

Recentes avanços nas sínteses orgânicas catalisadas por sólidos ácidos e básicos com a irradiação microondas permitem que muitas reações sejam feitas na ausência de quaisquer solventes orgânicos. O princípio destas reações é a irradiação microondas sobre os reagentes em conjunto com catalisadores sólidos.

As reações orgânicas com catálise heterogênea têm sido muito aplicadas no contexto industrial. Estas reações são acompanhadas com sucesso devido ao fato que os catalisadores suportados em compostos porosos apresentam uma ótima dispersão dos sítios reativos, aumentando a seletividade e a eficiência das reações tradicionais. Os suportes sólidos usados nestas reações podem ser reciclados e reutilizados como catalisadores destas reações. As reações aceleradas pela irradiação microondas envolvem a absorção seletiva da radiação microondas pelas moléculas polares, já as moléculas apolares são inertes à perda dielétrica na região das microondas ${ }^{41-44}$. Os experimentos iniciais com a técnica de microondas centravam-se no uso de solventes com altos coeficientes dielétricos, tais como dimetilsulfóxido e dimetilformamida, causando um superaquecimento durante as reações. Porém, a aplicação da técnica de microondas floresceu recentemente com os estudos de reações sobre suportes sólidos, em condições livres de solventes. Nestas reações, os compostos orgânicos adsorvidos nas superfícies de óxidos inorgânicos, tais como alumina, sílica gel, argilas ou suportes modificados, absorvem irradiação microondas, ao passo que os suportes sólidos não absorvem esta irradiação. A temperatura na estrutura inorgânica durante a reação é relativamente baixa, porém, durante o processo as temperaturas junto aos reagentes na superfície do suporte são extremamente altas durante a irradiação microondas. As reações assistidas pela irradiação microondas na ausência de quaisquer solventes proporcionam a oportunidade de se trabalhar com frascos abertos, evitando riscos de altas pressões ${ }^{41}$.

Uma enorme gama de reações podem ser feitas por este procedimento; dentre esta miríade de processos pode-se destacar reações de n-alquilação, como a n-alquilação de ftalimidas na presença de brometo de tetrabutilamônio suportado em carbonato de potássio (Figura 7).

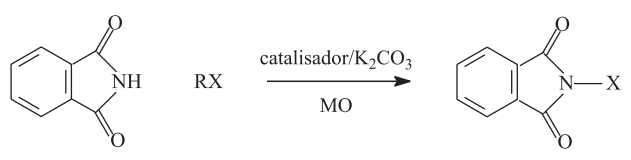

Figura 7. Reação ftalato de fenila com um haleto de alquila, catalisado por tetrabutilamônio suportado em carbonato de potássio, acelerada por irradiação na região de microondas

A clivagem de acetatos também pode ser obtida por irradiação, sendo um processo rápido, na ordem de segundos. Diacetatos derivados de aldeídos aromáticos são rapidamente clivados sobre a superfície de alumina neutra durante uma breve exposição à radiação microondas (Figura 8).<smiles>[X]c1ccc(C=C(C)C(C)=O)cc1</smiles>

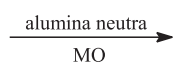<smiles>[X]c1ccc(C=O)cc1</smiles>

Figura 8. Clivagem de um diacaceto de haletos de benzaldeído catalisada por alumina neutra, induzida por irradiação na região de microondas

Reações de oxidação também têm sido acompanhadas pelo processo livre de solventes mais a irradiação microondas. A oxidação de arenos com o permanganato suportado em alumina tem apresentado resultados muito bons (Figura 9).
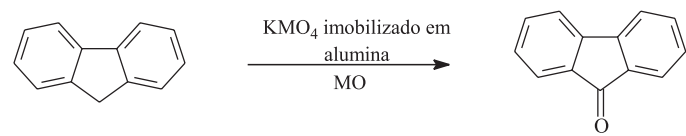

Figura 9. Oxidação de areno catalisada por permanganato de potássio, induzida pela irradiação na região de microondas

Este procedimento abre inúmeras possibilidades para o desenvolvimento de reações orgânicas mais eficientes, que geram menos subprodutos, baseando-se em reagentes suportados em óxidos inorgânicos. A química limpa deste procedimento reacional apresenta distintas vantagens, desde a eliminação dos solventes nas reações, até a maior seletividade na formação dos produtos. Conseqüentemente, pode-se dizer que esta metodologia é uma forma elegante de se aplicar a química verde nas reações químicas já vastamente exploradas. 


\section{Fluido supercrítico}

Outro método reacional na ausência de solventes é a aplicação de fluidos supercríticos ao processo.

A reatividade das moléculas usando o fluido supercrítico está baseada na alta temperatura da água ou do $\mathrm{CO}_{2}$, que se apresentam no estado supercrítico ${ }^{45-48}$. A aplicação desta técnica em processos industriais tem minimizado os problemas com os resíduos formados. As mudanças nas propriedades físicas e químicas da água e do $\mathrm{CO}_{2}$ no estado supercrítico têm encorajado muitos pesquisadores a se aventurarem nesta linha de pesquisa. A diminuição da permissividade da água e do gás carbônico implica no aumento da solubilidade de compostos orgânicos nestes fluidos ${ }^{45-48}$. O aumento das constantes dielétricas no estado supercrítico também favorece as reações catalisadas por sólidos ácidos e básicos ${ }^{45-48}$.

Reações como a oxidação do 2,6-di-terc-butilfenol catalisada por $\mathrm{N}, \mathrm{N}$ '-bis(salicilideno)-etilenoimina de cobalto II podem ser realizadas na ausência de solventes orgânicos, através da aplicação do fluido supercrítico de $\mathrm{CO}_{2}$, conforme a reação apresentada na Figura 10.<smiles>CC(C)(C)c1cccc(C(C)(C)C)c1O</smiles>

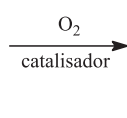

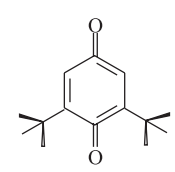

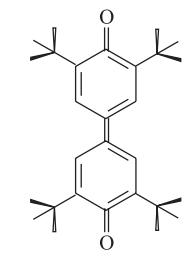

Figura 10. Oxidação de 2,6-tercbutilfenol em fluido supercrítico de $\mathrm{CO}_{2}$

\section{Fotocatálise}

Outros processos de catálise também são aplicados para a obtenção de maior eficiência e menor geração de subprodutos. Recentes avanços nas pesquisas dos processos de foto-oxidações catalíticas mostram a grande potencialidade da aplicação da fotocatálise seletiva em procedimentos que se enquadram nos princípios fundamentais da química verde. As reações catalisadas pela ação da irradiação da luz são processos que usam materiais semicondutores e solventes não tóxicos. Geralmente o $\mathrm{TiO}_{2}$ anatase é o material semi-condutor mais usado, o qual pode estar associado com sílica gel ou óxidos inorgânicos para facilitar a sua recuperação. A excitação deste semicondutor é feita através da irradiação da luz ultravioleta <390 nm. O alto grau de oxidação tem sido demonstrado pela ativação fotocatalítica de hidrocarbonetos, compostos aromáticos, bem como a destruição completa de poluentes ambientais ${ }^{49}$. A aplicação da fotocatálise em reações orgânicas deve ser destacada como um dos métodos de extrema importância no desenvolvimento de reações verdes ${ }^{50,51}$.

As reações fotoinduzidas em solvente aquoso têm se mostrado importante ferramenta em potencial para transformações seletivas e limpas em química orgânica. $\mathrm{O}$ sal de bis-potássio de n-ftatalimidaácido glutâmico pode ser descarboxilado seletivamente em água, através da fotoirradiação a $380 \mathrm{~nm}$, conforme a Figura 11.
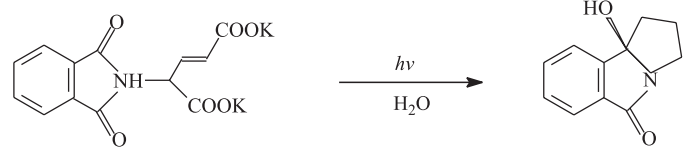

Figura 11. Descarboxilização do sal de bis-potássio de n-ftalimida de ácido glutâmico, induzida por fotocatálise a $380 \mathrm{~nm}$

\section{Biocatálise}

O uso da atividade microbiana para catalisar reações químicas pode ser aplicado em diversas sínteses com sucesso ${ }^{52,53}$. As reações biocatalisadas representam uma extensão das rotas clássicas de síntese com significantes reduções nos impactos ambientais gerados pelos processos clássicos. A biocatálise também é um dos processos que podem ser explorados no desenvolvimento da química verde. A alta régio e estéreo seletividade das bioconversões pode simplificar os processos industriais, aumentando o rendimento e diminuindo a geração de subprodutos ${ }^{52,53}$.

Uma grande variedade de processos químico-enzimáticos tem sido desenvolvida em larga escala na modificação de N-heterociclos aromáticos. Compostos piridínicos são convertidos facilmente pela ação de microrganismos.

Reações como a oxidação da 3-cianopiridina são muito aplicadas industrialmente, usando microrganismos para catalisar as reações. A hidrogenação da 3-cianopiridina, bem como a produção da vitamina $\mathrm{B}_{3}$ usando a biocatálise têm sido aplicadas, com sucesso, nos processos químicos com grande seletividade (Figura 12).

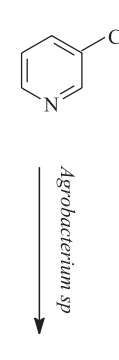<smiles>O=C(O)c1ccc(O)nc1</smiles>

Figura 12. Hidrogenação da 3-cianopiridina catalisada pela Agrobacterium sp e conversão da 3-cianopiridina em vitamina $B_{3}$, catalisada por Rhodococus rhodochorus

\section{Desenvolvimento de compostos de menor toxicidade}

O aprimoramento de compostos comerciais com o objetivo da diminuição de sua toxicidade também tem sido destaque na ciência verde atual. $\mathrm{O}$ ancoramento de agroquímicos comerciais em superfícies de sílica (Figura 13) está sendo estudado para aumentar a sua efetividade, diminuindo as perdas com lixiviação e degradação microbiana com uma efetiva diminuição de sua toxicidade. Os resultados<smiles>Nc1c(Cl)c(Cl)nc(C(=O)O)c1Cl</smiles><smiles>CC1CO[Si](O)(CCl)OC(C)CO1</smiles><smiles>C=C[Te]</smiles><smiles>CC1CC(CO)O[Si](C)(O)OC(C)CO1</smiles>

Figura 13. Ancoramento do agroquímico picloram em cloropropilssílica 
destes agroquímicos ancorados são promissores, apresentando maior durabilidade do material e evitando a aplicação de quantidades excedentes nos campos agrícolas, sem afetar drasticamente a microbiota dos solos onde estes agroquiímicos são aplicados ${ }^{54-57}$.

\section{Processos catalíticos em sistemas bifásicos}

A utilização de sistemas bifásicos em transformações catalíticas de substratos orgânicos tem-se mostrado como alternativa promissora aos processos catalíticos homogêneos e heterogêneos ${ }^{58}$. Os processos bifásicos apresentam atividades e seletividades similares aos processos homogêneos, com a grande vantagem da possibilidade da reutilização dos catalisadores como nos processos heterogêneos. Assim, os processos bifásicos aliam as vantagens dos processos homogêneo e heterogêneo ${ }^{58}$.

O processo catalítico bifásico ocorre usando dois líquidos imiscíveis, um contendo o catalisador e o outro, o substrato. Os líquidos são colocados em contato e a reação catalítica ocorre em uma das fases, nas duas ou na interface dos líquidos ${ }^{59}$. No final do processo ocorre a separação das fases, o catalisador encontra-se dissolvido em uma delas e os produtos em outra, o que facilita a reutilização dos catalisadores, bem como a separação dos produtos, conforme apresentado na Figura 14. O aumento do rendimento do processo reacional devido à catálise, a facilidade na separação dos produtos e a reutilização dos catalisadores são princípios fundamentais da química verde.

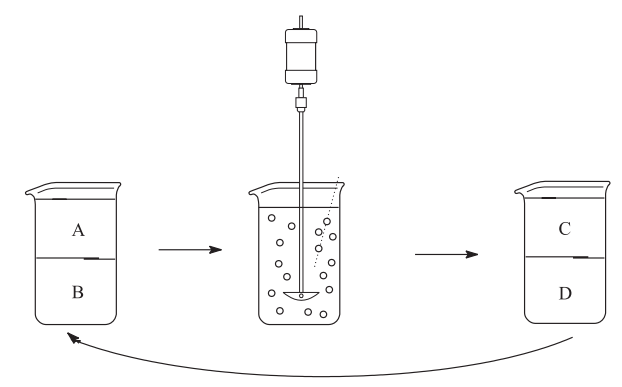

Figura 14. Processo catalítico bifásico. (A) líquido 1, contendo o substrato; (B) líquido 2, contendo o catalisador; (C) líquido 1, contendo o produto; (D) líquido 2 contendo o catalisador

Dentre os diversos processos de catálise bifásica, recentemente, os compostos denominados líquidos iônicos ou sais fundidos vêm sendo empregados com grande sucesso em processos catalíticos e de extração ${ }^{60-63}$. Os sais fundidos podem ser definidos como líquidos que apresentam estruturas iônico-covalentes. Assim, esta definição envolve desde compostos inorgânicos puros (cloreto de sódio), os quais apresentam altos pontos de fusão e altas viscosidades, até misturas de sais orgânicos e inorgânicos (compostos organominerais), tais como cloreto de trietilamônio/cloreto de alumínio, que apresentam pontos de fusão à temperatura ambiente e baixos valores de viscosidade $^{60}$.

Os sais derivados de associações de haletos 1,3-imidazólio e haletos de alumínio apresentam propriedades muito atrativas dentre os líquidos iônicos, tais como: i) pontos de fusão baixos, permitindo reações à temperatura ambiente; ii) baixas solubilidades em hidrocarbonetos e altas densidades, que facilitam a separação dos produtos formados e dos catalisadores no líquido iônico; iii) são ácidos de Lewis, os quais apresentam as mais diversas propriedades catalíticas desde polimerizações tipo Ziegler-Nata até reações de Friedel-Crafts ${ }^{60}$.

\section{Química Verde na escola}

Estes conceitos devem ser introduzidos e aplicados para a formação de profissionais qualificados às necessidades do novo milênio $^{64}$.

Muitos cursos de química apresentam a química ambiental em seus currículos. Porém, poucos apresentam os conceitos laboratoriais sobre a prevenção da geração de subprodutos indesejáveis e tóxicos ao ambiente ${ }^{65,66}$, que é o princípio fundamental da química verde, assim como no desenvolvimento de práticas de laboratório de ensino adaptadas a este novo conceito da química ${ }^{67-71}$. A implementação da química verde nos currículos universitários está começando no mundo, e o interesse em seus materiais educacionais vem crescendo, sendo que muitos recursos educacionais em química verdes têm sido desenvolvidos ou estão em pleno desenvolvimento ${ }^{12,64,72,73}$.

O código de conduta da American Chemical Society afirma: "Os químicos têm a responsabilidade profissional de servir ao interesse público e ao bem-estar, através dos seus conhecimentos científicos. Os químicos deverão ter cuidados com a saúde e o bem-estar dos companheiros de trabalho, consumidores e da comunidade; deverão compreender e antecipar as conseqüências ambientais do seu trabalho. Os químicos têm a responsabilidade de evitar a poluição e proteger o meio ambiente". Tal código mostra a preocupação das entidades científicas com uma química responsável, e corrobora os princípios da chamada química verde ${ }^{74}$.

O interesse no uso da química verde nos processos químicos tradicionais tem sido estendido internacionalmente para a prevenção da poluição nos países desenvolvidos. Esta evolução é marcada por significantes contribuições de instituições que procuram o desenvolvimento alternativo e sustentável da química ${ }^{12,75}$. O crescimento da área de química verde no consciente acadêmico resulta na formação de profissionais que podem desenvolver metodologias científicas e tecnológicas com aspectos positivos para o planeta $^{75}$.

\section{Presença brasileira}

O Brasil também apresenta pesquisadores que se aventuram na direção de um desenvolvimento sustentável da química. Na revista científica direcionada a esta linha de pesquisa, Green Chemistry, já existe a participação brasileira no desenvolvimento da ciência ver$\mathrm{de}^{76-79}$. Pesquisas brasileiras na área de desenvolvimento de catalisadores sólidos, que apresentam a grande vantagem de sua reutilização com o objetivo de aumentar o rendimento da reação e diminuir a formação de subprodutos, podem ser encontradas na literatura científica corrente ${ }^{79-80}$. Estratégias de desenvolvimento de sistemas de fluxo seqüencial para a diminuição do uso de reagentes, através do seu tratamento e reciclagem on-line também têm sido desenvolvidas por nossa química nacional ${ }^{78}$. A modificação de produtos comerciais tornando-os substancialmente menos tóxicos também é um dos destaques da ciência brasileira nesta filosofia de pesquisa, sendo reconhecido internacionalmente pelo jornalismo científico ${ }^{81}$. O ancoramento de substâncias quelantes em matrizes sólidas para a remoção de contaminantes de solventes é outra linha de pesquisa que vem sendo desenvolvida. ${ }^{34-36,76}$. A modificação de procedimentos sintéticos para o aumento do rendimento das reações ${ }^{82,83}$, bem como para eliminação de solventes orgânicos usados durante os processos, tem sido um dos caminhos percorridos pela nossa química ${ }^{84}$.

\section{CONSIDERAÇÕES FINAIS}

Tendo em mente o fundamento da necessidade da eliminação de compostos tóxicos, que em muitas ocasiões tornam-se dificultosos, deve-se então voltar à busca da transformação dos mesmos em subs- 
tâncias de menor toxidez, bem como, na diminuição da geração de novos compostos tóxicos, que envolvem processos químicos tradicionais. Assim, tem-se a cada dia o maior aprimoramento dos objetivos propostos pela química verde. Esta linha de desenvolvimento científico está alicerçada no estudo da preparação de novos materiais com propriedades catalíticas para o desenvolvimento de processos com menor quantidade de subprodutos e de solventes tóxicos, no desenvolvimento de compostos essenciais com menores níveis de toxicidade, bem como na aplicação de materiais npara a remoção de contaminantes inorgânicos e orgânicos dispersos nos mananciais. Desta forma, estes serão os focos de pesquisa de uma ciência consciente dos potenciais impactos causados por sua aplicação irracional.

A utilização efetiva e cotidiana da química verde é o grande desafio a ser vencido. Para isso, é necessária a formação de pessoal com consciência em um desenvolvimento sustentável, a regulamentação de leis rígidas no âmbito ambiental e o desenvolvimento de processos verdes mais econômicos, os quais são os pilares para o enraizamento desta filosofia científica, para que ela se torne cotidiana nas práticas científicas e tecnológicas ao redor do planeta.

\section{AGRADECIMENTOS}

Ao prof. P. A. Z. Suarez pelas valiosas discussões e a V. O. Santos Jr. pela revisão do manuscrito.

\section{REFERÊNCIAS}

1. Poliakoff, M.; Fitzpatrick, J. M.; Farren, T. R.; Anastas, P. T.; Science 2002, 297, 807.

2. Graedel, T.; Green Chem. 1999, 1, G126.

3. Clark, J. H.; Green Chem. 1999, 1,1 .

4. Tundo, P.; Anastas, P.; Black, D. S.; Breen, J.; Collins, T.; Memoli, S.; Myiamoto, J.; Polyakoff, M.; Tumas, W.; Pure Appl. Chem. 2000, 72, 1207.

5. Clark, J. H.; Macquarrie, D. J.; Chem. Commun. 1998, 853.

6. Clark, J. H.; Macquarrie, D. J.; Chem. Soc. Rev. 1996, 303.

7. Price, P. M.; Clark, J. H.; Macquarrie, D. J.; J. Chem. Soc., Dalton Trans. 2000, 101

8. Anatas, P. T.; Kirchhoff, M. M.; Acc. Chem. Res. 2002, 35, 686.

9. Bresson, C.; Menu, M. J.; Dartiguenave, M.; Dartiguenave, Y.; J. Environ. Monit. 2000, 2, 240.

10. Stein, A.; Melde, B. J.; Schoden, R. C.; Adv. Mater. 2000, 12, 1403.

11. Hjeresen, D. L.; Schutt, D. L.; Boese, J. M.; J. Chem. Educ. 2000, 77, 1543.

12. Matlack, A.; Green Chem. 1999, 1, G19.

13. Mozeto, A. A.; Jardim, W. F.; Quim. Nova 2002, 25 - Supl. 1, 7.

14. Thornton, J.; Pure Appl. Chem. 2001, 93, 1231.

15. Winterton, N.; Green Chem. 2001, 3, G73.

16. Trost, B. M.; Science 1991, 254, 1471.

17. Trost, B. M.; Angew. Chem., Int. Ed. 1995, 34, 259.

18. Macquarrie, D. J.; Phil. Trans. R., Soc. Lond. A 2000, 358, 419.

19. Macquarrie, D. J.; Green Chem. 1999, 1, 195.

20. Kurt, K.; Asefa, T.; Coombs, N.; Jaroniec, M..; Ozin, G. A.; J. Mater. Chem. 2002, 12, 3452 .

21. Richer, R.; Mercier, L.; Chem. Mater. 2001, 13, 2999.

22. Tanev, P. T.; Chibwe, M.; Pinnavaia, T. J.; Nature 1995, 368, 321.

23. Macquairre, D. J.; Chem. Commun. 1996, 1961.

24. Tanev, P. T.; Pinnavaia, T. J.; Science 1995, 267, 865.

25. Bagshaw, S. A.; Prouzet, E.; Pinnavaia, T. J.; Science 1995, 269, 1241.

26. Prouzet, E.; Pinnavaia, T. J.; Angew. Chem., Int. Ed. 1997, 36, 516.

27. Barton, T. J.; Bull, L. M.; Klemperer, W. G.; Loy, D. A.; McEnaney, B.; Misono, M.; Monson, P. A.; Pez, G.; Scherer, G. W.; Vartulli, J. C.; Yaghi, O. M.; Chem. Mater. 1999, 11, 2633.

28. Chen, C. Y.; Li, H. X.; Davis, M. E.; Microporous Mesoporous Mater. 1993 , 2,17 .
29. Macquarrie, D. J.; Jackson, D. B.; Tailland, S.; Uting, K.; J. Mater. Chem. 2001, 11, 1843.

30. Blanc, A. C.; Macquarrie, D. J.; Valle, S.; Renard, G.; Quin, C. R.; Brunel, D.; Green Chem. 2000, 2, 283.

31. Utting, K; Macquarrie, D. J.; Appl. Catal., A 2002, 232, 7.

32. Wilson, K.; Lee, A. F.; Macquairre, D. J.; Clark, J. H.; Appl. Catal., A 2002, $228,127$.

33. Macquarrie, D. J.; Nazih, R.; Sedti, S.; Green Chem. 2002, 4, 56.

34. Clark, J. H.; Pure Appl. Chem. 2001, 73, 103.

35. Wilson, K.; Clark, J. H.; Pure Appl. Chem. 2000, 72, 1313.

36. Prado, A. G. S.; Airoldi, C.; Anal. Chim. Acta 2001, 432, 201.

37. Prado, A. G. S.; Airoldi, C.; Fresenius'J. Anal. Chem. 2001, 321, 1028.

38. Prado, A. G. S.; Arakaki, L. N. H.; Airoldi, C.; J. Chem. Soc., Dalton. Trans. 2001, 2206.

39. Cave, G. W. V.; Raston, C. L.; Scott, J. L.; Chem. Commun. 2001, 2159.

40. Bandgar, B. P.; Uppalla, L. S.; Kurule, D. S.; Green Chem. 1999, 1, 243.

41. Varma, R. S.; Green Chem. 1999, 1, 43

42. Varma, R. S.; Meshram, H. M; Tetrahedron Lett. 1997, 38, 5427.

43. Varma, R. S.; Saini, R. K.; Tetrahedron Lett. 1997, 38, 2623.

44. Varma, R. S.; Saini, R. K.; Tetrahedron Lett. 1998, 39, 1481.

45. Jessop, P. G.; Ikariya, T.; Noyori, R.; Chem. Rev. 1999, 99, 475.

46. Aleman, P. A.; Boix, C.; Poliakoff, M.; Green Chem. 1999, 1, 65.

47. Cooper, A.; Poliakoff, M.; Green Chem. 1999, 1, G167.

48. Wei, M.; Musie, G. T.; Busch, D. H.; Subramaniam, B.; J. Am. Chem. Soc. 2002, 124, 2513.

49. Higarashi, M. M.; Jardim, W. F.; Am. Lab. 2000, 32, 25.

50. Gonzalez, M. A.; Howell, S. G.; Sikdar, S. K.; J. Catal. 1999, 183, 159.

51. Griesbeck, A. G.; Kramer, W.; Oelgemoller, M.; Green Chem. 1999, 1, 205.

52. DeSantis, G.; Zhu, Z.; Greenberg, W. A.; Wong, K.; Chaplin, J.; Hanson, S. R.; Farwell, B.; Nicholson, L. W.; Rand, C. L.; Welner, D. P.; Robertson, D. E.; Burk, M. J.; J. Am. Chem. Soc. 2002, 124, 9024.

53. Petersen, M.; Kiener, A.; Green Chem. 1999, 1, 99.

54. Prado, A. G. S.; Airoldi, C.; Pest Manage. Sci. 2000, 56, 419

55. Prado, A. G. S.; Airoldi, C.; J. Colloid Interface Sci. 2001, 236, 161.

56. Prado, A. G. S.; Airoldi, C.; Thermochim. Acta 2002, 394, 155.

57. Airoldi, C.; Prado, A. G. S.; Thermochim. Acta 2002, 394, 163

58. Dupont, J.; Quim. Nova 2000, 23, 825.

59. Darendourg, D. J.; Stafford, N. W.; Joo, F.; Reibenspies, J. H.; J. Organomet. Chem. 1995, 488, 99.

60. Dupont, J.; de Souza, R. F.; Suarez, P. A. Z.; Chem. Rev. 2002, 102, 3667.

61. Suarez, P. A. Z.; Dullius, J. E. L.; Einloft, S.; de Souza, R. F.; Dupont, J.; Polyhedron 1996, 15, 1217.

62. Dupont, J.; Consorti, C. S.; Spencer, J.; J. Braz. Chem. Soc. 2000, 11, 337.

63. Dupont, J.; Suarez, P. A. Z.; Umpiere, A. P.; de Souza, R. F.; J. Braz. Chem. Soc. 2000, 11, 293.

64. Sater, L.; Green Chem. 2000, 2, G72.

65. Collins, T. J.; J. Chem. Educ. 1995, 72, 965.

66. Cann, M. C.; J. Chem. Educ. 1999, 76, 1639.

67. Reed, S. M.; Hutchison, J. E.; J. Chem. Educ. 2000, 77, 1627.

68. Raston, C. L.; Scott, J. L.; Pure Appl. Chem. 2001, 73, 1257.

69. Raston, C. L.; Scott, J. L.; Green Chem. 2000, 2, 49.

70. Scott, J. L.; Raston, C. L.; Green Chem. 2000, 2, 245.

71. Warner, M. G.; Succaw, G. L.; Hutchison, J. E.; Green Chem. 2001, 3, 267.

72. Kirchhoff, M. M.; J. Chem. Educ. 2001, 78, 1577.

73. Heinhorst, S.; Cannon, G.; J. Chem. Educ. 2001, 78, 150.

74. Ware, S. A.; Pure Appl. Chem. 2001, 73, 1247.

75. Hjeresen, D. L.; Anastas, P.; Ware, S.; Kirchhoff, M.; Environ. Sci. Technol. 2001, 35, 105A.

76. Prado, A. G. S.; Arakaki, L. N. H.; Airoldi, C.; Green Chem. 2002, 4, 42

77. Prado, A. G. S.; Airoldi, C.; Green Chem. 2002, 4, 288.

78. Rocha, F. R. P.; Nóbrega, J. A.; Fatibello, O.; Green Chem. 2001, 3, 216.

79. Van Vliet, M. C. A.; Mandelli, D.; Arends, I. W. C. E.; Schuchardt, U.; Sheldon, R. A.; Green Chem. 2001, 3, 243.

80. Dupont, J.; Quim. Nova 2002, 25 - Supl. 1, 12.

81. http://www.chemweb.com/alchem/articles/1022229043944.html, acessada em Setembro 2002.

82. Sanseverino, A. M.; Quim. Nova 2000, 23, 102.

83. Sanseverino, A. M.; Quim. Nova 2002, 25, 660.

84. Prado, A. G. S.; Airoldi, C.; J. Mater. Chem. 2002, 12, 3823. 